\title{
Erratum to: Determination of a terrestrial reference frame via Kalman filtering of very long baseline interferometry data
}

\author{
Benedikt Soja $^{1}$ - Tobias Nilsson ${ }^{1}$ - Kyriakos Balidakis ${ }^{2}$ - Susanne Glaser ${ }^{2}$. \\ Robert Heinkelmann ${ }^{1}$ - Harald Schuh ${ }^{1,2}$
}

Published online: 12 September 2016

(C) Springer-Verlag Berlin Heidelberg 2016

\section{Erratum to: J Geod (2016)}

DOI 10.1007/s00190-016-0924-7

Due to a production error, the references to Figs. 1 and 2 were mixed up in the text at three occasions (at the end of Sect. 2, in Sect. 3.1, and within the caption of Fig. 3).

The online version of the original article can be found under doi:10.1007/s00190-016-0924-7.

\footnotetext{
Benedikt Soja

benedikt.soja@gfz-potsdam.de

1 GFZ German Research Centre for Geosciences, Potsdam, Germany

2 Institute for Geodesy and Geoinformation Science, Technische Universität Berlin, Berlin, Germany
} 